\title{
Studies on the Delay of Smoke Detector Alarm in Underground Engineering
}

\author{
Di Zhang ${ }^{1, a^{*}}$, Xiao-Ping Miao ${ }^{1, b}$ and Feng Jiang ${ }^{1, c}$ \\ ${ }^{1}$ College of Defense Engineering, PLA University of Science and Technology, Nanjing, Jiangsu, \\ China \\ azhangdirm@163.com, bmxp57@163.com, ${ }^{\mathrm{b}}$ feeling602@163.com
}

Keywords: Underground engineering; Ventilation and air conditioning system; Smoke detector

Abstract: Based on numerical simulation, the delay of smoke detector alarm was studied in this paper. The air velocity fields and smoke concentrations were introduced in to help to analyze the impact of detector location and air supply velocity on the detector alarm performance. The results revealed that the position of smoke detector had a great influence on the alarm time. Inappropriate installation position delayed the alarm; meanwhile, the delay was aggravated with larger air inlet velocity. It is of great significance to study the pattern of fire and smoke spread to determine the feasibility of a fire test system.

\section{Introduction}

In the underground engineering, the smoke detector is usually installed in the middle position of the roof. And the detector performs well under no wind conditions ${ }^{[1]}$. However, when the ventilation and air conditioning system is running, the airflow organization would be different in the room. The smoke would spread with the airflow in the early stage of fire. The smoke detectors can not sent the alarm information timely, which would increase the risk of fire ${ }^{[2][3]}$.

The ventilation and air conditioning system was different according to the location and direction of the wind pipe. The mounting position of smoke detector should relate to the different air supply mode. This paper studied the smoke spread characteristic of two typical underground engineering air supply modes based on the numerical simulation. The conclusion can guide the mounting position of smoke fire detector.

\section{Model description}

The continuous equation and mass equation of the control volume of smoke's plume in underground engineering are as follows:

$$
\begin{aligned}
& \frac{\partial \rho}{\partial t}+\frac{\partial(\rho u)}{\partial x}=0 \\
& \rho c_{p}\left(\frac{\partial T}{\partial t}+u \frac{\partial T}{\partial x}\right)=-\lambda \frac{\partial^{2} T}{\partial x^{2}}-\frac{a}{h}\left(T-T_{0}\right)
\end{aligned}
$$

where $\rho$ is the ambient air density, $u$ is the characteristic velocity, $c_{p}$ is the specific heat capacity, $T$ is the smoke temperature, $T_{0}$ is the ambient air temperature, $\lambda$ denotes the thermal conductivity, $h$ and $a$ are the smoke layer depth and coefficient of heat transfer.

The state equation is $p v=n R T$, we can get:

$$
\rho T=\rho_{0} T_{0}
$$

After derivation, the continuous equation is obtained:

$T \frac{\partial(\rho u)}{\partial x}=\rho \frac{\partial T}{\partial t}$

The energy equation are as follows: 


$$
\begin{aligned}
& \frac{\partial(\rho u T)}{\partial x}=\frac{\partial\left(\rho_{0} u T_{0}\right)}{\partial x}=-\frac{a}{c_{p} h}\left(T-T_{0}\right) \\
& \frac{d u}{d x}=-\frac{a \Delta T_{0}}{c_{p} \rho_{0} T_{0} h}
\end{aligned}
$$

When $\Delta T=0$, the $u=0$, if it's other case, the velocity profile can be expressed as follow:

$$
\left\{\begin{array}{l}
\frac{d u}{d x}=-\frac{a \Delta T_{0}}{c_{p} \rho_{0} T_{0} h} e^{-K\left(x-x_{0}\right)} \\
x=x_{0}, u=u_{0}
\end{array}\right.
$$

The paper chooses two typical air supply and return mode in the underground engineering: up-supply and up-return, lateral-supply and downside-return, to calculate the problem using the fire dynamic simulation software $\operatorname{FDS}^{[4][5]}$. The air inlet of up-supply condition and air outlet of up-return are on the top of the room, the air intake of the lateral-supply and air outtake of the downside-return mode are on the wall. The two modes are shown in figure 1 and figure 2.

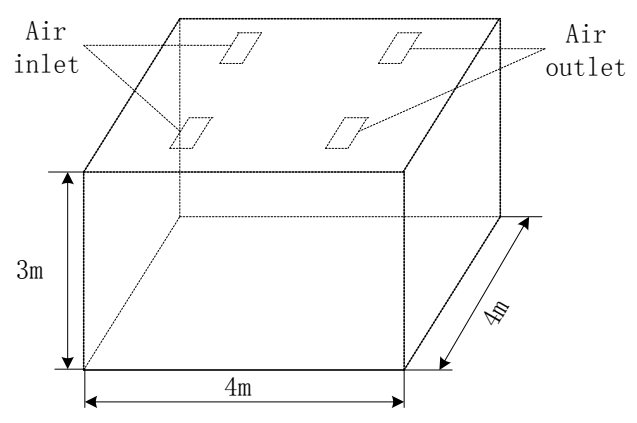

Figure 1. Up-supply and up-return mode

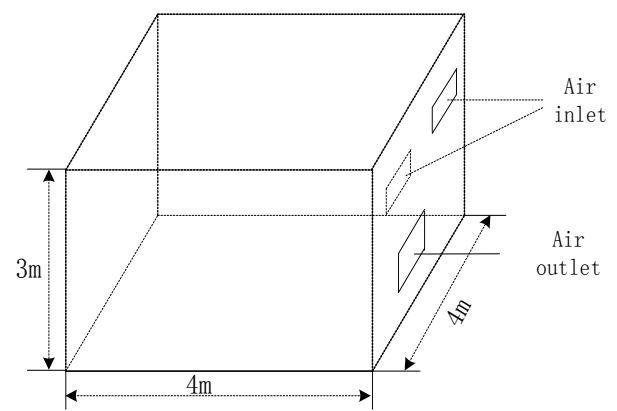

Figure 2. Lateral-supply and downside-return mode

The mesh cells size in the model is $0.1 \mathrm{~m} * 0.1 \mathrm{~m} * 0.1 \mathrm{~m}$. A T2-incresaing heat release rate of $800 \mathrm{~kW} / \mathrm{m} 2$ fire is established. The fire burns to completely stage at $100 \mathrm{~s}$ and the combustion area is $30 \mathrm{~cm}^{*} 30 \mathrm{~cm}$. The air inlet in up supply mode is $40 \mathrm{~cm} * 20 \mathrm{~cm}$ and the size of the door as air outlet in down-return mode is $40 \mathrm{~cm} *$ $40 \mathrm{~cm}$.

Decorate 7 smoke detector (SD01 SD07) at the top of the room as shown in figure 3. It is primary to make the detector SD04 be in center of the roof. According to the national standard of China, the sensitivity of smoke detector which can be measured by the concentration of smoke is $3.28 \% / \mathrm{m}^{[6]}$. Design 8 cases in the process of simulation as shown in table 1 . The up-up represents the air mode of up-supply and up-return, the lateral-down represents for the lateral-supply and downside-return mode.

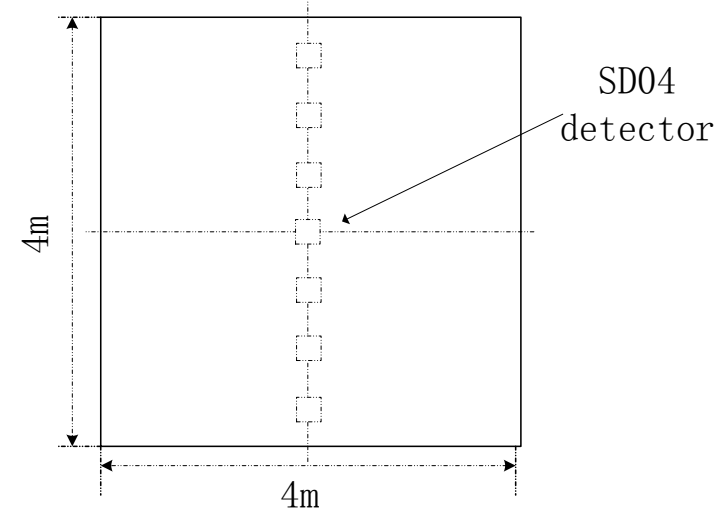

Table 1 Design of simulation program

\begin{tabular}{ccccc}
\hline number & s1 & s2 & s3 & s4 \\
\hline mode & up-up & up-up & up-up & up-up \\
velocity & 0.25 & 0.5 & 0.75 & 1 \\
\hline number & s5 & s6 & s7 & s8 \\
\hline \multirow{2}{*}{ mode } & Lateral & Lateral & Lateral & Lateral \\
& -down & -down & -down & -down \\
velocity & 0.25 & 0.5 & 0.75 & 1 \\
\hline
\end{tabular}

Figure3 The layout of smoke detector 


\section{Result and analysis}

\section{Up-supply and up-return mode}

In the mode of up-supply and up-return, the velocity of the air inlet is $0.25 \mathrm{~m} / \mathrm{s}, 0.5 \mathrm{~m} / \mathrm{s}, 0.75 \mathrm{~m} / \mathrm{s}$ and $1 \mathrm{~m} / \mathrm{s}$ respectively. Set the start simulation after 100s to make sure that the airflow organization has stabilized. In each kind of air velocity, the alarm time of 7 detectors from SD01 to SD07 is shown in table 2.

Table 2 Alarm time of detector in up-up mode

\begin{tabular}{lccccccc}
\hline & SD01 & SD02 & SD03 & SD04 & SD05 & SD06 & SD07 \\
\hline Alarm time $(0.25 \mathrm{~m} / \mathrm{s})$ & $129.9 \mathrm{~s}$ & $128.3 \mathrm{~s}$ & $126.4 \mathrm{~s}$ & $121.5 \mathrm{~s}$ & $117.8 \mathrm{~s}$ & $124.3 \mathrm{~s}$ & $128.4 \mathrm{~s}$ \\
Alarm time $(0.5 \mathrm{~m} / \mathrm{s})$ & $132.6 \mathrm{~s}$ & $131.5 \mathrm{~s}$ & $127.5 \mathrm{~s}$ & $124.2 \mathrm{~s}$ & $121.5 \mathrm{~s}$ & $118.2 \mathrm{~s}$ & $128.0 \mathrm{~s}$ \\
Alarm time $(0.75 \mathrm{~m} / \mathrm{s})$ & $135.0 \mathrm{~s}$ & $133.9 \mathrm{~s}$ & $131.2 \mathrm{~s}$ & $128.6 \mathrm{~s}$ & $125.8 \mathrm{~s}$ & $122.5 \mathrm{~s}$ & $122.5 \mathrm{~s}$ \\
Alarm time $(1 \mathrm{~m} / \mathrm{s})$ & $137.4 \mathrm{~s}$ & $135.6 \mathrm{~s}$ & $133.4 \mathrm{~s}$ & $130.8 \mathrm{~s}$ & $130.5 \mathrm{~s}$ & $126.6 \mathrm{~s}$ & $125.7 \mathrm{~s}$ \\
\hline
\end{tabular}

$\mathrm{T}$ is set as the first alarm time, and the value of $\mathrm{T}$ is $117.8 \mathrm{~s}, 118.2 \mathrm{~s}, 122.5 \mathrm{~s}, 125.7 \mathrm{~s}$ for four kinds of air velocity respectively. We can get 4 pictures of smoke concentration in each air velocity, which are shown in figure 4.

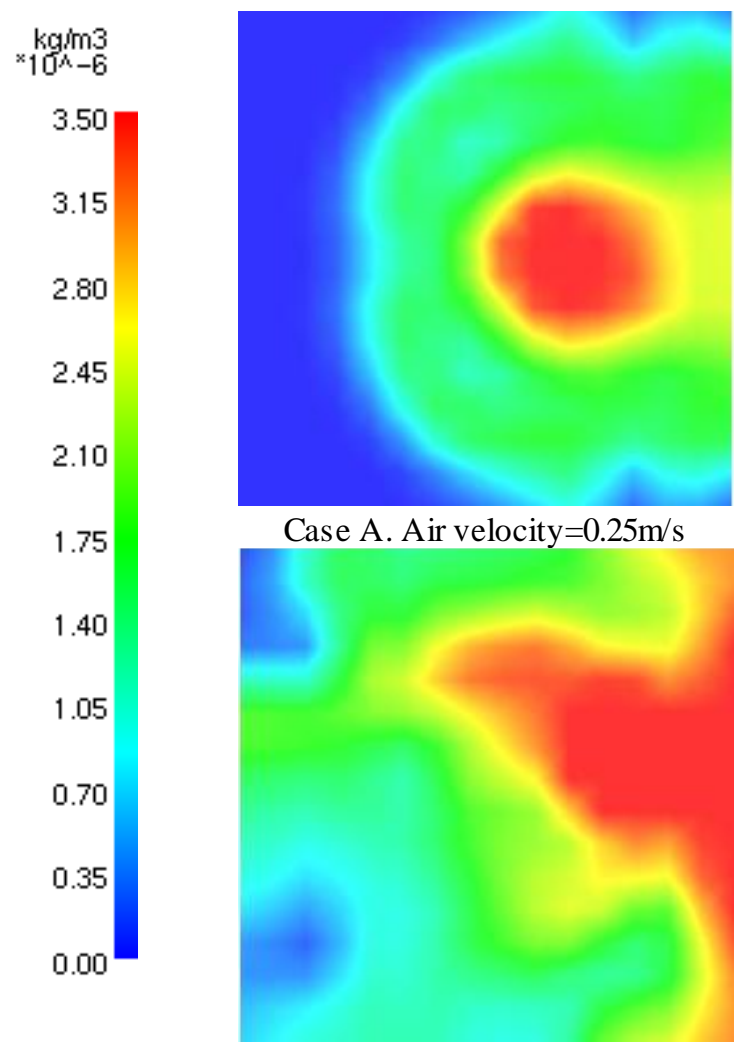

Case C. Air velocity $=0.75 \mathrm{~m} / \mathrm{s}$

Figure 4 Smoke concentration in up-up mode at $\mathrm{T}$

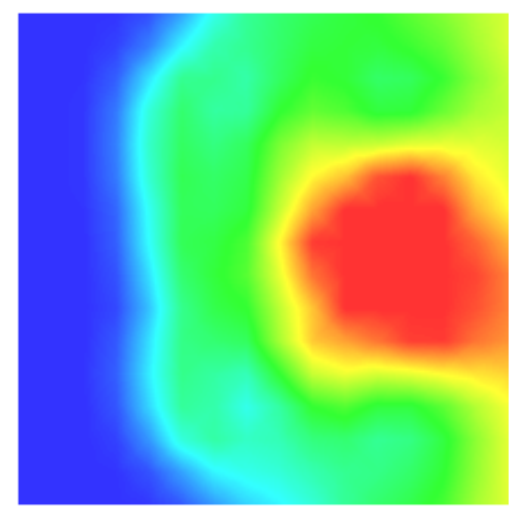

Case B. Air velocity $=0.5 \mathrm{~m} / \mathrm{s}$

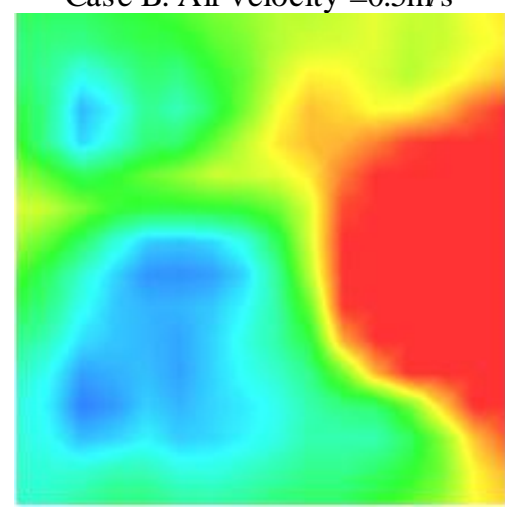

Case D. Air velocity $=1 \mathrm{~m} / \mathrm{s}$

By analyzing the smoke concentration figures, the smoke is mainly concentrated in the right side of the roof in the up-up mode. With the increase of air supply velocity, this kind of situation was pronounced, and the smoke detector which was closer to the air outlet of return could alarm the fire hazard more quickly. It should be point out that the delay phenomenon of the detector is more obvious in the room of high velocity air supply.

\section{Lateral-supply and downside-return mode}

In the lateral-supply and downside-return mode, the air inlet of supply was on the above of the door. The alarm time of the detector in the middle of the roof, named SD04, is $121.0 \mathrm{~s}, 130.7 \mathrm{~s}, 133.1 \mathrm{~s}$ and $135.4 \mathrm{~s}$, for four different air supply velocities. It was not the earliest detector which alarmed the fire hazard as predicted. SD05 alarmed the fire at $115.2 \mathrm{~s}$ in the air velocity of $0.25 \mathrm{~s}$, and the detector which alarmed earliest in other three air velocity is SD06,SD07 and SD07, separately. The lag time of SD04 was shown in figure 5. And the smoke concentration in four air velocity was shown in figure 6 . 


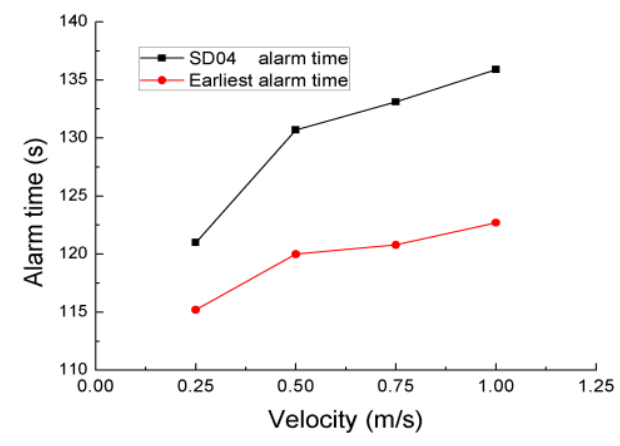

Figure 5 Lag time of SD04 smoke detector

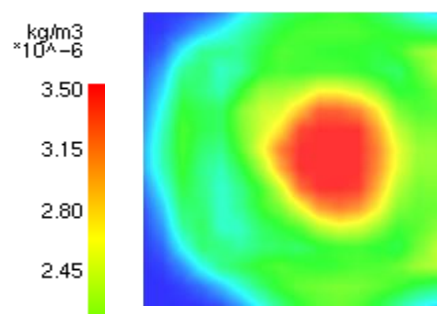

E.velocity $=0.25 \mathrm{~m} / \mathrm{s}$

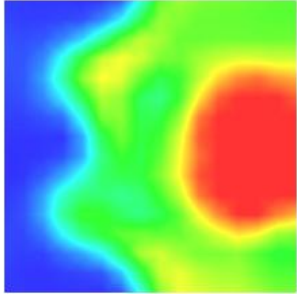

G. velocity $=0.75 \mathrm{~m} / \mathrm{s}$

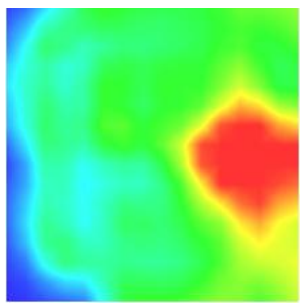

F. velocity $=0.5 \mathrm{~m} / \mathrm{s}$

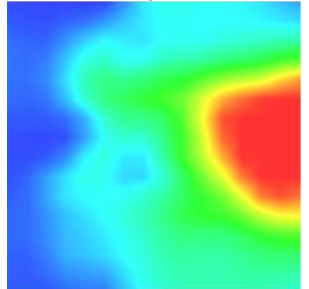

H. velocity $=1 \mathrm{~m} / \mathrm{s}$

Figure 6 Smoke concentration in lateral-down mode at T

\section{Conclusion}

The performance of the smoke detector alarm was studied is this paper. The optimized installation location was obtained for two different air supply modes.

(1) As for the up-supply and up-return mode, the location of smoke detector near the air outlet vent performed best, with earliest alarm time.

(2) Compared to mode of the up-supply and up-return, the smoke concentration distribution in the lateral-supply and down return mode is more regular. And the smoke detector installed on the side of roof which was closer to the air inlet and air outlet could alarm the fire hazard earlier.

\section{References}

[1] Huo Ran, Hu Yuan and Li Yuanzhou. Introduction of the building fire safety engineer [M]. Hefei: University of Science and Technology of China Press, 1999. 32

[2] O.Keski-Rahkonen. Revisiting modeling of fluid penetration into smoke detectors for low speed ceiling jets [A].12th International Conference on Automatic Fire Detection(AUBE’01) [C]. March 25 28, 2001.

[3] Thomas Cleary, Artur Chernovsky, William Grosshan-dler and Melissa Anderson. Particulate entry lag in spot-type smoke detectors [A]. Sixth International symposium. International Association for Fire Safety Science (IAFSS) [C]. July 5 7, 1999.

[4] J. E. Floyd, K. B. Mc Grattan, S. Hostikka, et al. CFD fire simulation using mixture fraction combustion and finite volume radiation heat transfer [J]. Journal of fire protection engineering, 2003(13):11-36.

[5] Sung Ryong Lee, Hong Sun Ryou. A numerical study on smoke movement in longitudinal ventilation tunnel fires for different aspect ratio[J]. Building and Environment,2006, 41:719-725.

[6] Qualey J R, Desmarais III L, Pratt J. Response-time comparison of ionization and photoelectric/heat detectors [A]. International conference on automatic fire detection "AUBE'01" 12th proceedings [C]. Gaithersburg, MD: National Institute of Standard and Technology, 2001. 283 299. 